\title{
On the Cultivation of English Majors' Literary Attainments in the Light of New National Standard
}

\author{
Yana Wen", a, Dongzhi Liu², b \\ ${ }^{1}$ College of Foreign Languages, Bohai University, Jinzhou 121000, China; \\ ${ }^{2}$ College of Education and Sports, Bohai University, Jinzhou 121000, China. \\ awendywenyana@163.com, b23812889@qq.com
}

\begin{abstract}
The new national standard for foreign language teaching in Chinese universities emphasizes the cultivation of English major students' literary attainments which help to improve students' cognition of English culture and contribute to improve students' all-round abilities to use English. To achieve this purpose, some new measures should be taken in literature teaching, for example, setting up an up-to-date teaching database, creating a good learning atmosphere, combining in-and-after class teaching, setting up an effective appraisal system.
\end{abstract}

Keywords: literary attainments; national standard; English major.

\section{Introduction}

English major was established quite early in Chinese universities, and until now it has become a major of the largest scale. Since 1980s, English education has made great achievements in China. Now, there are 1448 universities at the undergraduate level, among which 994 universities have English major [1]. With the expansion of English major comes but the decrease of education quality, which violates the educational requirements. In addition, with the integration of China into the world, the demand for English majors keeps increasing, and the present national standard is barely adaptive. Therefore, to guarantee the teaching quality and meet the requirement of the society, a new national standard is urgently needed. Under such circumstances, the Teaching Guiding Committee for College Foreign Language Majors attached to the Chinese Ministry of Education (2013-2017) was set up in 2013. In its inaugural meeting, Liu Guiqin, the Deputy Director of Higher Education Department, said that the main task of the Committee is to develop a new national standard for majors of foreign languages. Led by Professor Zhong Weihe, all the specialists in the Committee, worked to draft the new standard that is expected to meet all in the second half of 2016. The draft emphasizes the importance of cultivating English majors' literary attainments which is agreed by most as an effective way to solve the existing problems confronting English majors [2].

Many problems are confronting English majors, among which the most dangerous one I think is the over-emphasis on the utility of English language and the overlook of its nature as the humanities. English as any other language is a tool for people to communicate, but it is also a bridge to understand another country and another culture. Language came into being from people's communication. Different races have different languages, which results from the progress of human civilization, so each language symbolizes different culture. Sapir observed language was a part of culture and a part of human behavior. It was often held that the function of language was to express thought and to communicate information. Language also fulfilled many other tasks such as greeting people, conducting religious service, etc. The Sapir-Whorf hypothesis stated that our language determined the way we think and view the world [3]. The negligence of its humanistic nature is a fault more than a problem. And as the storehouse of human language, literature is also the collection of brilliant human ideas and the museum of human history and culture. Therefore, the cultivation of students' literary attainments is of great value. First, it helps to improve students' cognition of English culture. Novels, dramas, poets, and essays, they all reflect the culture in different ways through detailed description of the mind and the life of people at a certain place in a certain period. While reading, students play the role of a co-author, acquire an insight into English society, and thus see the world in a different light. Second, it contributes to improve students' all-round abilities to use English. It is 
well known that the input lays the foundation for the effective output of any language. Literary works with large vocabulary and various sentence structures serve as a practical channel for students to expand their English world and to reinforce their correct use of English.

\section{Training Strategies}

\subsection{Setting up an Up-to-date Teaching Database}

Now there are a large number of paper teaching books about both English and American literature. Each book has its unique way of editing, so the use of a single teaching book is not sufficient to develop students' literary sensitivity. It is necessary for teachers to select and provide some reference books and even some research papers for students to compare, to find and to probe into the essence of literature.

In most Chinese universities, teaching materials for literature are mostly published paper books or additional materials printed by teachers, which is hardly enough in this online reading era when young people prefer to read via computers or mobile phones. Therefore, some electric teaching materials should be included. Lin Lan, from Jiaying college in Guangdong province, recommended setting up a database with multiple electric and printed teaching materials. Her database includes electric teaching plans on both American literature and British literature, five pieces of electric auxiliary reading materials, five lectures on English literature and 13 pieces of audio-visual materials as well as the text books, all of which are attached with related questions. What's more, five learning websites emphasizing different aspects of literature are also accessible to students [4]. This teaching database makes for the cultivation of students' interests and their active learning of literature. And with the rapid development of micro-lectures and the application of many useful APPs in these several years, the database will be constantly instilled with new things and becomes more powerful.

\subsection{Creating a Good Learning Atmosphere}

The draft of New Standard highlights the training of students' literary attainments and redesigns the curriculum on literature. The courses include History of British and American Literature, the Reading of British and American novels and poems, the Reading and Acting of British dramas, Bible stories, Greek and Roman Mythology, Introduction to Literary Criticism, Comparative Literature. Almost all the courses are arranged in Grade Three, which may hustle students too much and cause their perfunctory work. Rome was not built in a day, likewise, the literary attainments can not be obtained overnight. A research from Huang Lifeng proves that in most universities, students start learning literature from Grade Three, and without enough accumulation of common knowledge about literature, together with limited reading time and intense input of literary knowledge, students feel hard to digest and fail to appreciate the beauty of literature [5]. Another research from Cheng Aimin observed that over $50 \%$ of the teachers supported adding teaching time, which was objected by $86 \%$ students. Accordingly, Cheng suggested that the training should start from Grade One. In addition, the difficulty of teaching materials should vary according to students' different interests and abilities [5]. Base on Mr. Cheng's suggestion, I think it's a good choice to select teaching materials from some easy works like prose and short stories because such works with simple words and sentence structures can easily attract students' attention. What is more important is that students should be immersed in a literary atmosphere to develop their interests. An effective way to achieve this, I think, is to have literary education permeate all the courses that are seemingly irrelevant to literature-intensive reading, extensive reading, speaking, writing, listening. For example, in a typical intensive reading class in China, the students will be asked to search and present some background information about the texts at the beginning of class, mostly about some famous writers or literary concepts, which lay the basis for the later learning of literary courses. For example, through the learning of the short story The Dill Pickle by Katherine Mansfield, students may access to some basic literary knowledge like Symbolism and Modernism and through reading the writer's other works, students will have a better understanding of the writer and her writing style. Now, many classics have been adapted to films, the seeing of which may help to arouse students interests in literature. Likewise, in listening or speaking class, teachers can also find some literary works for students to appreciate and imitate, for example, 
the famous English poet William Blake's poem The Tiger and The House on Mango Street from Sandra Cisneros are all interesting and readable literary works. Through progressive learning of literary works and with a scientific curriculum, students will eventually develop their literary attainments.

\subsection{Combining In-and-after Class Teaching}

The cultivation of students' literary attainments mainly depends on literature courses, so it is important to maximize the teaching effects, which may be achieved by the combining of in-and-after class activities. Professor Zhang Aiping once said the best-accepted way to teach literature was the traditional way, that is, the combination of the teacher's brief explanation and the class discussion, to spur the efficient interaction between the teacher and the students and the students themselves [6]. In most Chinese universities, the main teaching method of literature for now is the traditional method, too. But the class size, I think, is the biggest challenge to the effective implement of this method. In most Chinese universities, there are 60 students or so in a literature class, which dwarfs the expected teaching objective. And an inspiring discussion requires much accumulation of reading, which is absent in most students. A research carried out by Huang Lifeng observed that the most popular teaching method for literature favored by students was film appreciation (about $88 \%$ ), the rests are PPT display (66\%), discussion (48\%), and role-play (44\%).[7] Therefore, in addition to the traditional face-to-face teaching, some additional methods supported by modern technology deserve a try in the cyber era. In class, PPT has already become the most popular auxiliary teaching method, and after class, IM serves as the bridge between teachers and students. That is to say, a healthy cyber atmosphere for teaching literature is a good supplement for class teaching, which demands teachers' elaborate plan and students' great devotion and cooperation. First, teachers are supposed to select the important and difficult points, arrange the teaching plan and objectives, encourage and instruct students to find related information from the internet. Second, in class, based on what students found in advance, teachers can impress students with some audio-visual materials, provoking students' interest and strengthen their understanding of literary works. After class, teachers can deliver some literary criticism to students via the net to study and review in accordance with their own schedule, ability and even interest, and meanwhile teachers can supervise students' understanding of the lesson. In short, the teaching of literature should combine the in-and-after class activities together.

\subsection{Setting up an Effective Appraisal System}

To ensure the enhancement of the students' literary attainments, an effective appraisal system is indispensable, and it is the guarantee of teaching quality. It includes formative evaluation and summative evaluation. The formative evaluation can be carried out through e-folders. Teachers set up an e-folder for each student, in which there are students' personal learning experiences, term papers and routine assignments, etc. the routine assignments are better to suit for different students. The summative evaluation is better to be an open-book exam. The research from Huang Lifeng revealed that $67 \%$ of the students approved of the routine assignments as the appraisal method, $44 \%$ of the term papers and almost no one was willing to take a closed-book exam [7]. The research showed that compared with cramming for exam by memorizing a corps of data, students preferred thinking and translating their thoughts into papers. If the final exam is necessary, subjective questions should be the choice. Questions based on the understanding of the novel and its significance in its time are helpful to the improvement of students' literary attainments. In brief, the appraisal system differs from teacher to teacher, and it should match with every aspect of the course, only so, can the appraisal system be effective.

\section{Summary}

Challenged by the increase of social demands and the decrease of teaching quality, English major in Chinese universities is facing reform, under which circumstances, a new national standard is under study. The draft of the standard emphasizes the cultivation of students' literary attainments. As a result, literature teaching has to take measures to meet the requirement, for example, setting up an up-to-date teaching database, creating a good learning atmosphere, combining in-and-after class 
teaching, setting up an effective appraisal system. All the measures suggested by this paper may help to enhance the teaching effect and improve students' literary attainments. However, there is not a panacea for all problems, and the effect remains to be tested.

\section{References}

[1] Junju Wang. On Curriculum Design of the National Standards for Undergraduate English-major Student: Review and Reflections. Modern Foreign Languages. Vol. 38 (2015) No. 1, p121-130.

[2] Information on: www.fltrp.com

[3] Information on: www.en.wikipedia.org

[4] Lan Lin. Research on the Stereoscopic Teaching Mode in English Majors' Literature Teaching. Work and Study Abroad. (2010) No.23, p98-100

[5] Lifeng Huang. Research and Reflection on English majors' Literature Teaching in Universities. Jiangsu Foreign Language Teaching and Research. (2010) No.1, p19-22.

[6] Jian Yang. Common Practice in Literary Offerings in the English Departments of America Universities. Vol.34 (2012) No. 5, p9-16

[7] Lifeng Huang. Research and Reflection on English Majors' Literature Teaching in Universities. Jiangsu Foreign Language Teaching and Research. (2010) No.1, p19-22. 